\title{
A paisagem e o território no ensino escolar de Geografia
}

\author{
Landscape and territory in school education of Geography
}

\author{
Aurino Alves Nunes Filho'; Diego Salomão Candido de Oliveira Salvador"l
}

\begin{abstract}
RESUMO
O espaço é categoria filosófica que pode servir às reflexões, análises e interpretações de variadas ciências e áreas de conhecimentos. Para a Geografia, tal categoria é especificada em geográfico, sendo, desse modo, considerada como conceito-chave da ciência e da disciplina escolar. O espaço geográfico diz respeito à totalidade, sendo que, para se estudá-lo de modos específicos, deve-se recorrer às suas dimensões analíticas, a saber: paisagem, território, região e lugar. Cada dimensão tem particularidades quanto à forma e ao conteúdo do espaço, podendo ser estudada por meio das categorias analíticas forma, função, estrutura e processo. Destarte, via dimensões e categorias analíticas, o espaço geográfico pode ser analisado ou interpretado enquanto (re)produção social. A paisagem é a dimensão do espaço caracterizada pela morfologia e pelas representações ou significações humanas e sociais; o território é particularizado pelas relações de poder e de produção; a região pela fragmentação e articulação do espaço total visando a sua gestão; e o lugar pela afetividade e pelas relações global-local. Quanto às categorias analíticas do espaço, a forma é o visível; a função, o conteúdo da forma; o processo, a história da produção e da reprodução do espaço; e a estrutura o todo decorrente desse processo, isto é, a forma-conteúdo do espaço. Os conceitos de paisagem e território são conceitos-chave no contexto da história do pensamento geográfico, mantendo-se, no contexto atual, como conceitos importantes para a compreensão da dinâmica do espaço globalizado. Neste trabalho, refletimos sobre os conceitos de paisagem e território no ensino escolar de Geografia. Para isso, refletimos sobre esses conceitos enquanto dimensões do espaço, analisamos as orientações presentes em documentos oficiais da Educação Básica nacional quanto aos referidos conceitos e analisamos como estes são abordados em livros didáticos de Geografia.
\end{abstract}

Palavras-chave: Paisagem; Território; Ensino de Geografia

\section{ABSTRACT}

Space is a philosophical category that can serve to reflect, analyze and interpret different sciences and areas of knowledge. For Geography, this category is specified in geographic, and is thus considered as a key concept of science and school discipline. Geographical space concerns totality, and in order to study it in specific ways, one must resort to its analytical dimensions, namely: landscape, territory, region and place. Each dimension has particularities regarding the form and content of the space, and can be studied through the analytical categories: form, function, structure and process. Thus, via analytical dimensions and categories, geographic space can be analyzed or interpreted as social (re)production. The landscape is the dimension of space characterized by morphology and by human and social representations or meanings; the territory is particularized by the relations of power and production;

' Professor do Estado do Rio Grande do Norte - RN, Brasil - aurino.santacruz@yahoo.com.br

"Professor do Departamento de Geografia da UFRN- RN, Brasil - diegosalomao84@hotmail.com 
the region due to the fragmentation and articulation of the total space for its management; and the place for affectivity and global-local relations. As for the analytical categories of space, the form is the visible; the function, the content of the form; the process, the history of space production and reproduction; and the structure of the whole resulting from this process, that is, the form-content of space. The concepts of landscape and territory are key concepts in the context of the history of geographical thought, remaining, in the current context, as important concepts for understanding the dynamics of globalized space. In this work, we reflect on the concepts of landscape and territory in school teaching Geography. For this, we reflect on these concepts as dimensions of space, we analyze the guidelines present in official documents of the national Basic Education regarding these concepts and we analyze how they are approached in Geography didatic books.

Keywords: Landscape; Territory; Geography teaching

\section{INTRODUÇÃO}

Em artigo publicado em 1988 na Revista Terra Livre, Milton Santos apresenta o espaço enquanto categoria filosófica, que, portanto, pode servir às reflexões, análises e interpretações de variadas ciências e áreas de conhecimentos. Para a Geografia, tal categoria é especificada em geográfico, sendo, desse modo, considerada como conceito-chave da ciência (SPOSITO, 2004) e da disciplina escolar. Santos (1996) sublinha que o espaço geográfico diz respeito à totalidade, sendo que, para se estudálo de modos específicos, deve-se recorrer às suas dimensões analíticas, a saber: paisagem, território, região e lugar. Cada dimensão tem particularidades quanto à forma e ao conteúdo do espaço, podendo ser estudada por meio das categorias analíticas forma, função, estrutura e processo (SANTOS, 2008). Destarte, via dimensões e categorias analíticas, o espaço geográfico pode ser analisado ou interpretado enquanto (re)produção social.

Com esse entendimento, destaca-se que a paisagem é a dimensão do espaço caracterizada pela morfologia e pelas representações ou significações humanas e sociais; o território é particularizado pelas relações de poder e de produção; a região pela fragmentação e articulação do espaço total visando a sua gestão; e o lugar pela afetividade e pelas relações global-local. Quanto às categorias analíticas do espaço, Santos (2008) esclarece que a forma é o visível; a função, o conteúdo da forma; o processo, a história da produção e da reprodução do espaço; e a estrutura o todo decorrente desse processo, isto é, a forma-conteúdo do espaço. 
Assim, Santos (1978) realça que o espaço geográfico é social, por ser produto das ações de diferentes e desiguais agentes sociais. Enquanto produto humano, o espaço é também uma instância social, tendo em vista o fato de a configuração atual do espaço influenciar as novas ações que são desenvolvidas no processo de (re)produção do espaço. Desse modo, o espaço geográfico é reflexo da sociedade e condição para as atuais ações humanas.

Os conceitos de paisagem e território são conceitos-chave no contexto da história do pensamento geográfico, mantendo-se, no contexto atual, como conceitos importantes para a compreensão da dinâmica do espaço globalizado.

Neste trabalho, refletimos sobre os conceitos de paisagem e território no ensino escolar de Geografia. Para isso, refletimos sobre esses conceitos enquanto dimensões do espaço, analisamos as orientações presentes em documentos oficiais da Educação Básica nacional quanto aos referidos conceitos e analisamos como estes são abordados em livros didáticos de Geografia.

\section{REFLEXÕES SOBRE O CONCEITO DE PAISAGEM}

A paisagem está para o geógrafo assim como a arte está para o homem. O ser humano primitivo já observava a paisagem e a esculpia nas rochas, mostrando o cotidiano bem como a sua relação com o espaço. Desta forma, até o início do século XIX, momento da fundação da ciência geográfica, a paisagem era entendida apenas como uma pintura, isto é, obra de arte. Contudo, a partir do citado momento, a paisagem passa a ter também um caráter geográfico, sendo entendida como a fisionomia de determinado espaço, seu aspecto visível.

Humboldt ${ }^{1}$, em suas viagens de estudos, ao observar espaços que fossem homogêneos ou tivessem elementos que pudessem Ihes dar unidade - do ponto de vista da morfologia do solo e da cobertura vegetal, definia tais espaços de paisagens naturais ou landschaft. Conforme Tricart (1981), a influência das ciências naturais

\footnotetext{
${ }^{1}$ Alexander von Humboldt (1769-1859), naturalista alemão, é um dos fundadores da ciência geográfica, estudando esta como a ciência do cosmos, isto é, da totalidade da superfície terrestre.
} 
sobre os geógrafos alemães fazia com que eles definissem a paisagem pela composição de elementos como o relevo, o solo e as plantas, não destacando as modificações produzidas pelo homem.

Assim, na Geografia Clássica (da segunda metade do século XIX à primeira metade do século XX), conforme Salgueiro (2001), a paisagem foi estudada por meio do método morfológico ou do método corológico. Pelo primeiro método, Humboldt compreendia a paisagem pela sua forma física, isto é, dando conta da descrição e da análise dos elementos naturais da paisagem. Na perspectiva do método corológico, Sauer $^{2}$ e La Blache ${ }^{3}$ estudaram a paisagem pelos seus atributos físicos e humanos, apreendendo as relações entre sociedade e natureza, explicando essas relações pelo conceito de gênero de vida, que refere-se aos modos específicos de cada povo viver e se relacionar com a natureza. Com o estudo de diferentes paisagens, se poderia comparar diferentes gêneros de vida e, assim, se chegar ao entendimento de totalidades.

À medida que a história do pensamento geográfico foi sendo evoluída, o entendimento de paisagem foi sendo fundamentado na relação sociedade e natureza, com foco na transformação histórica da paisagem natural em paisagem cultural ou geográfica, conforme as ações humanas. Assim sendo, o conceito de paisagem aproxima as perspectivas física e humana em Geografia, tendo-se em vista o fato de a morfologia da paisagem ser caracterizada pelos fenômenos da natureza e pela sociedade.

Com esse sentido, Sauer (1998) definiu a paisagem como unidade geográfica, sendo uma forma da Terra cujo processo de modelagem não é restritamente físico. A paisagem é composta pela combinação de distintas formas-conteúdos, tanto físicas quanto culturais. Destarte, a paisagem não é constituída apenas pelo solo, pela

\footnotetext{
2 Carl Ortwin Sauer (1889-1975), geógrafo clássico norte-americano, dedicou-se ao estudo da transformação histórica da paisagem natural em paisagem cultural, por meio da compreensão da relação homem-natureza.

3 Paul Vidal de La Blache (1845-1918), geógrafo clássico francês, estudou a região enquanto unidade espacial particular e relacionada a outras unidades. Cada região seria caracterizada por gênero de vida resultante da relação homem-natureza. O estudo detalhado e comparado das diversas regiões de um dado país, significaria a compreensão da Geografia universal ou total desse espaço nacional.
} 
cobertura vegetal e pelos corpos hídricos. É dinamizada também pelo trabalho humano, ou seja, pela ação do homem em transformar os espaços.

Além disso, Sauer (1998) sublinha que, no entendimento da relação entre sociedade e natureza, o geógrafo privilegia o caráter antropocêntrico da morfologia da paisagem, analisando as transformações que os homens imprimem no espaço, por meio de técnicas e de relações desenvolvidas historicamente. Assim, em Geografia, as características valorizadas da paisagem são as que tem valor de habitat, seja no presente ou no futuro. Nessa perspectiva, Sauer (1998, p. 29) afirma que "o conteúdo da paisagem é encontrado, portanto, nas qualidades físicas da área que são importantes para o homem e nas formas do seu uso da área, em fatos de base física e fatos da cultura humana".

Segundo o entendimento proposto por Sauer (1998), a análise da paisagem deve levar em consideração a inseparabilidade entre tempo e espaço, pois, a morfologia da paisagem está em constante processo de modificação, com as históricas transformações da natureza pelo homem, bem como por meio das manifestações culturais colocadas em baila pelas sociedades. Dessa maneira, o que outrora era predominantemente paisagem natural, hoje é, cada vez mais, paisagem geográfica, no sentido da artificialização da natureza pelos homens. Acerca disto, Sauer (1998, p. 56) assevera que "a paisagem natural está sendo submetida a uma transformação nas mãos do homem, o último é para nós o fator morfológico mais importante. Por meio de suas culturas faz uso das formas naturais, em muitos casos alterando-as, em alguns destruindo-as".

Conforme Sauer (1998), a paisagem cultural é moldada a partir de uma paisagem natural e por intermédio das ações de um grupo cultural. A cultura entendida como o modo de vida de uma sociedade - seria o agente capaz de guiar toda a transformação; a área natural seria o meio a ser modificado; e a paisagem cultural seria o resultado de todo o processo. Diante disso, a paisagem natural fornece a configuração inicial para que a paisagem cultural seja formada. No entanto, 
é esta última a que mais interessa ao homem, uma vez que ela é essencialmente o espaço geográfico - o espaço modificado pelo homem.

Também privilegiando a totalidade da relação sociedade-natureza, porém, com outra perspectiva de foco de estudo, na década de 1970, foi atribuído ao conceito de paisagem o entendimento sistêmico. Assim, Bertrand (2004) propôs o estudo da paisagem combinando elementos físicos, biológicos e antrópicos, reagindo dialeticamente uns sobre os outros e fazendo da paisagem um conjunto único e indissociável. A paisagem enquanto sistema é, ao mesmo tempo, social e natural, subjetiva e objetiva, espacial e temporal, produção material e cultural, real e simbólica. Sendo assim, a paisagem não é apenas natural nem social; é total, com todas as implicações da produção humana e dos fenômenos da natureza.

Cosgrove (1998) destaca o estudo da paisagem pela relação entre cultura e poder. Para ele, a paisagem é uma maneira de ver o mundo, cuja criação é racionalmente ordenada e designada. Nesse sentido, define a paisagem como formas visíveis sobre a superfície da terra intimamente ligadas à cultura e ao poder.

Deste ponto de vista, o estudo da cultura tem relação com o estudo do poder, tendo-se em vista que as paisagens são construídas a partir da apropriação e da transformação do meio ambiente pelo homem, em que uma mesma sociedade pode ter culturas radicalmente distintas. Assim, uma paisagem pode evidenciar a coexistência de culturas diferentes, com a tentativa de diversos grupos sociais buscando impor as suas marcas, experiências e formas de produzir na morfologia e na representação do espaço.

Na perspectiva da cultura como poder, Cosgrove (1998) sugere a decodificação das paisagens simbólicas pela cultura dominante e culturas alternativas. No que se refere à cultura dominante, ela representa o poder de um grupo sobre outros. Esse domínio não se restringe apenas ao controle dos meios de vida - terra, capital e matéria-prima, mas também a imposição de valores, pela capacidade de projetar e comunicar uma visão de mundo que reproduz a própria experiência e que é aceita coletivamente como uma verdade (COSGROVE, 1998). Para que a cultura dominante 
se perpetue é necessário que as paisagens produzidas sob essa égide não sejam estáticas. Ao contrário, é necessária dinâmica às paisagens que reproduzem valores culturais. Assim, manifestações e significados são comuns e renovados no sentido de reforçar valores culturais dominantes característicos e transmitidos por paisagens.

No que tange às culturas alternativas, é importante analisá-las conforme as diferentes escalas geográficas. No âmbito global, as culturas alternativas são menos perceptíveis na paisagem. Porém, na escola local, uma cultura sem destaque global ou hegemônico pode ser dominante ou predominante. Todavia, Cosgrove (1998, p. 117) adverte que, "por mais dominante localmente que possa ser uma cultura alternativa, ela continua subdominante à cultura oficial [dominante, em escala global ou internacional]".

Com esse entendimento, Cosgrove (1998) tipifica as paisagens alternativas em residuais, emergentes e excluídas. As paisagens residuais se distinguem pela pouca relação com o seu significado original, havendo casos, inclusive, de serem desprovidas de qualquer significado. As paisagens emergentes se caracterizam pela diversidade, pelo caráter transitório e por sempre proporcionarem à cultura dominante um horizonte alternativo, diferente dos padrões estabelecidos no momento. As culturas excluídas, por sua vez, também estão inscritas na paisagem. Na paisagem citadina, sobretudo, elementos simbolizam determinados grupos não pertencentes a classes dominantes, como homossexuais e mendigos.

Na Geografia Crítica, Milton Santos ${ }^{4}$ entende a paisagem como uma dimensão concreta de análise do espaço geográfico. Assumimos tal concepção, com a compreensão de que a paisagem é um conjunto de formas que exprime o resultado de sucessivas relações existentes entre o homem e a natureza, com a coexistência de formas antigas e recentes.

Entendemos que a paisagem pode ser analisada a partir do seu aspecto visível, destacando-se tudo que a nossa visão for capaz de abarcar. Todavia, não é somente

\footnotetext{
${ }^{4}$ Milton Almeida dos Santos (1926-2001) foi um dos grandes expoentes da Geografia brasileira, desenvolvendo arcabouço sobre o espaço geográfico, enquanto objeto de estudo da ciência geográfica e instância da sociedade.
} 
pela visão que se pode ler e entender a paisagem. O tato, a audição e o olfato também podem gerar percepções desta dimensão de análise do espaço, uma vez que a paisagem é formada por cores, movimentos, odores, sons.

Atualmente, ainda existem dois tipos de paisagem: natural e artificial. A primeira, grosso modo, é a paisagem ainda não metamorfoseada pelo homem. Contudo, este tipo de paisagem está sendo cada vez mais extinto, pois, os homens vêm impactando direta ou diretamente todos os espaços da Terra, mais e mais. A paisagem artificial é aquela que carrega elementos culturais; meio alterado pelos homens. Devido ao fato de as paisagens atuais serem fruto das interações entre homem e natureza, acreditamos que a tendência é nos distanciarmos de um mundo natural em direção a um mundo artificial, na sua totalidade. Uma artificialização em diferentes níveis, mas total.

Santos (1996) também entende a paisagem como transtemporal, ou seja, marcada por objetos do passado e do presente, de modo transversal. Isto é, na paisagem atual existem elementos produzidos outrora, mas que resistem ao tempo e fazem parte da configuração atual do espaço. Para ele, cada paisagem se caracteriza por uma dada distribuição de formas, providas de um conteúdo técnico específico.

A paisagem reflete o movimento da história (SANTOS, 1988). A cada período histórico, ou a cada novo estágio do período atual, novas demandas são criadas e novas técnicas e objetos colocados em baila, imprimindo novas paisagens. Assim, a paisagem não surge do nada; ela evolui com a sociedade, à medida que o espaço é artificializado com a justaposição de objetos novos e antigos ou sobreposição daqueles sobre estes. Assim, a paisagem é uma herança de muitos momentos e expressão do presente.

Ao passo que o homem modifica a sua forma de produção, muda suas técnicas e acrescenta tecnologia ao seu modo de vida, os sistemas de objetos e de ações são alterados. Santos (2008, p. 67) afirma que "cada período se caracteriza por um dado conjunto de técnicas". Entretanto, tal mudança ocorre de maneira progressiva, com os 
elementos de tempos anteriores continuando a caracterizar o período atual. Assim, ficam impressos na paisagem elementos de tempos diferentes.

A dinâmica da paisagem é caracterizada por transformações funcionais ou estruturais (SANTOS, 1996). As mudanças funcionais decorrem do movimento funcional do espaço. Por exemplo, uma rua de uma cidade pode ter várias funções ao longo de um dia ou com o passar dos dias da semana. Durante o dia a rua pode ser um centro comercial, com fluxo constante de pessoas; à noite, esta mesma rua pode ser caracterizada pela violência e pelo tráfico de drogas. Durante um outro dia da semana, a rua pode ser o espaço de um mercado periódico, já durante outro dia pode ser lugar de festividade. A mudança estrutural decorre da alteração da totalidade ou da maioria da forma da paisagem, com a substituição de objetos antigos por inovações.

Afirmando que a paisagem é uma história congelada que participa da história viva, ou uma memória viva de um passado já morto, Santos (1996) entende a paisagem como um palimpsesto. Não obstante Santos (1996) afirmar que a paisagem participa da história do presente, ele é a denomina de palimpsesto e tal denominação, segundo Gandy (2004), é reducionista, por valorizar a paisagem, sobretudo, como uma imagem imobilizada eternamente. Eis as palavras de Gandy (2004, p. 85):

A paisagem urbana não é apenas um palimpsesto de estruturas materiais. É também o lugar onde se sobrepõem, de maneira singular e complexa, várias perspectivas e diversos símbolos culturais que não podem mais ser rebaixados à categoria de simples determinantes estruturais. [...] a paisagem é o lugar da superposição de jogos de poderes e de símbolos que têm influência na imaginação dos homens.

Dessa maneira, entendemos a paisagem como um conjunto de formasconteúdos decorrente das relações entre o homem e a natureza, com caráter transtemporal, tendo-se em vista expressar o passado, mas também participar da dinâmica do presente. 


\section{REFLEXÕES SOBRE O CONCEITO DE TERRITÓRIO}

Para Corrêa (1998), os conceitos de espaço e território não são sinônimos, apesar de alguns autores considerarem que eles têm o mesmo significado. Para nós, ao contrário, o território é uma dimensão concreta de análise do espaço geográfico, sendo, portanto, sinônimo de espaço habitado ou produzido pelos homens, por meio de relações de poder e de produção. Na história do pensamento geográfico, o território começou a ser discutido no contexto da Geografia Clássica, com destaque para os estudos do geógrafo clássico alemão Ratzel (1844-1904). Todavia, as análises acerca dessa dimensão do espaço foram substancialmente intensificadas com as abordagens que vêm sendo realizadas no âmbito da Geografia Crítica - corrente da história do pensamento geográfico colocada em tela desde a década de 1970.

Haesbaert (2004a) assevera que, desde a sua origem, o território é caracterizado por ser, ao mesmo tempo, material e simbólico, pois, genealogicamente, o termo está vinculado tanto a terra-territorium quanto a terreoterritor (terror, aterrorizar). Isto significa que o território tem íntima ligação com a dominação (jurídico-política) do solo e com a inspiração do terror em relação àqueles que não são possuidores de terras. Além disso, pode-se afirmar que quem usufrui do território tem uma identificação positiva e, assim, efetiva a apropriação do espaço.

Conforme Andrade (1998), para as ciências naturais o conceito de território está ligado a área de influência e dominação de determinada espécie animal. Já nas ciências sociais tal conceito está alinhado com a preocupação com o papel do Estado na gestão do território - concepção ratzeliana - e no que tange às relações entre as classes sociais e o espaço ocupado e dominado - compreensão sublinhada originalmente pelo geógrafo clássico francês Elisée Reclus (1830-1905).

Conforme Saquet (2007), até o século XV, a ideia de território estava vinculada apenas a dominação de determinadas áreas. A partir do século XVI, intensificou-se a difusão de doutrinas políticas que reforçaram a noção de soberania como um atributo dos Estados ou reinos. 
Nesse sentido, é inegável a simetria entre relações de poder e território. Ratzel - tratando da necessidade de unificação e afirmação do Estado alemão, no contexto da Geografia Clássica, desenvolveu estudos relacionando a Geografia com a política, abordando temas como Estado, fronteiras, relações internacionais, guerras. Desse modo, de modo original, utilizou o termo Geografia política (MORAES, 1990). Além disso, ele segmentou a Geografia em física, biogeografia e antropogeografia. Outrossim, propôs que a antropogeografia fosse subdividida em: as influências das condições naturais sobre a sociedade; o estudo das distribuições das sociedades humanas sobre o globo; e o estudo da formação dos territórios.

$\mathrm{Na}$ perspectiva ratzeliana, o território tem intrínseca relação com o poder estatal, sendo que, para ele, o Estado só existiria por meio da apropriação de território, afirmando que “o surgimento do Estado demandaria já um certo patrimônio cultural acumulado e teria por pressuposto a delimitação do território" (MORAES, 1990, p. 25). Do mesmo modo, Ratzel (1990) asseverou que a sociedade só seria uma Nação caso tivesse um território e um Estado.

Desse modo, Souza (1995, p. 84) afirma que

o território surge [...] como o espaço concreto em si (com seus atributos naturais e socialmente construídos), que é apropriado, ocupado por um grupo social. A ocupação do território é vista como algo gerador de raízes e identidade: um grupo não pode mais ser compreendido sem o seu território, no sentido de que a identidade sócio-cultural das pessoas estaria inarredavelmente ligada aos atributos do espaço concreto (natureza, patrimônio arquitetônico, paisagem).

É no território onde o homem vive e onde está assentada a sua história e as suas riquezas. Assim, para Ratzel (1990) "um povo decai quando sofre perdas territoriais". Nesse sentido, caberia ao Estado proteger o território de ameaças externas, de outros povos que não têm um vínculo com aquele solo. Outrossim, defende Ratzel que é na relação entre sociedade e território que se estabelece o formato do Estado. Esse relacionamento vai definir se o Estado é nômade, se tem 
governo militar, se tem tendência à democracia ou mesmo ao oligarquismo. Assim sendo, independente do grau de desenvolvimento de uma sociedade, ela sempre utiliza o território como fonte de moradia e obtenção de alimentos e o Estado como protetor.

Por outro lado, o território seria constituído a partir do espaço, sendo o resultado das ações desenvolvidas pelos homens no ambiente anterior. Ao se apropriar do espaço, os homens o territorializam, por meio da construção de casas, pontos comerciais, rodovias, ferrovias ou do fluxo de pessoas, mercadorias, capitais. Destarte, Raffestin (1993) define o território como o espaço onde os homens projetam um trabalho, isto é, um espaço produzido por intermédio de relações de poder.

Giuseppe Dematteis - geógrafo italiano - considera que o território é produto das relações de poder, apropriado pelo domínio exercido pela Igreja Católica, pelas grandes multinacionais, por grupos políticos e por supermercados (SAQUET, 2007). Ele argumenta que o território ultrapassa a realidade natural - denominada por ele como Terra ${ }^{5}$, sendo constantemente transformado em produto da socialização, constituído pelo comportamento humano, comunicação, cooperação e troca. Assim, o território é uma realidade material e técnica, pois, as contradições, tensões, conflitos internos, crises e mudanças dizem respeito à história do homem.

Souza (1995) coaduna com Ratzel (1990) e com Raffestin (1993) em que a característica basilar do território são as relações de poder. No entanto, no que tange à escala de análise, o geógrafo brasileiro destaca que o território não é apenas o território nacional:

A palavra território normalmente evoca o território nacional e faz pensar no Estado - gestor por excelência do território nacional -, em grandes espaços, em sentimentos patrióticos (ou mesmo chauvinistas), em governo, em dominação, em defesa do território pátrio, em guerras... A bem da verdade, o território pode ser entendido também à escala nacional em associação com o

\footnotetext{
${ }^{5}$ Para Dematteis (1985, p. 74), “a Terra é tornada território quando há comunicação, quando é meio e objeto de trabalho, de produção, de trocas, de cooperação".
} 
Estado como grande gestor [...]. No entanto, ele não precisa e nem deve ser reduzido a essa escala ou à associação com a figura do Estado. Territórios são construídos (e desconstruídos) nas mais diversas escalas [...] (SOUZA, 1995, p. 81).

Desse modo, Souza (1995) entende que o território é construído e desconstruído nas mais diversas escalas e temporalidades. O território pode se circunscrever a uma rua ou a espaços que superem os limites nacionais, bem como pode ser constituído por meio de séculos ou de dias. Outrossim, o território pode ser entendido pelas relações projetadas no espaço, já que a sua construção e dissolução podem ser concretizadas de modo relativamente rápido, como também pode configurar-se como estável ou instável, ou ter existência regular ou periódica. São exemplos destas situações os territórios da prostituição, das gangues, dos camelôs, do tráfico ou mesmo o território da Organização do Tratado do Atlântico Norte (OTAN).

Para Andrade (1998), o território não deve ser confundido com os conceitos de espaço ou de lugar, mas deve estar ligado a ideia de domínio ou de gestão de uma determinada área. Destarte, o território deve sempre estar vinculado ao poder, seja no âmbito estatal ou das grandes corporações.

Haesbaert (2004b) tipifica as acepções de território em quatro vertentes: a política, a cultural, a econômica e a natural. A vertente política - a mais difundida e que também pode ter um aspecto jurídico-político - se caracteriza pelas relações de poder no âmbito geral, bem como na sua forma institucionalizada. Sendo assim, o território é entendido como um espaço delimitado e controlado, de forma que, na maioria das vezes, o poder é exercido pelo poder do Estado. Na vertente cultural se prioriza a dimensão simbólica/subjetiva e o território é compreendido como produto da apropriação simbólica de um grupo em relação ao seu espaço vivido. Na vertente econômica, a dimensão espacial das relações econômicas ganha relevo, uma vez que o território é entendido como fonte de recursos e é incorporado no embate entre classes sociais e na relação capital-trabalho. Na acepção natural, o território é considerado a partir da relação entre sociedade e natureza. 
Assim, em qualquer acepção, o território está relacionado com o poder, mas não apenas ao tradicional poder político: “Ele diz respeito tanto ao poder no sentido mais concreto, de dominação, quanto ao poder no sentido mais simbólico, de apropriação" (HAESBAERT, 2004a).

Nessa perspectiva, Fuini (2017) frisa o território como um instrumento do poder político e da identidade cultural, por ser construído pelas relações de poder nas várias dimensões e escalas:

A concepção de território que Haesbaert traz é de uma dimensão espacial que se revela em processos de dominação mais concretos, tanto pela produção material quanto em termos jurídico-políticos. É também um espaço apropriado em termos imateriais na produção de identidade, subjetividade e simbolismos com certo lugar. O território também assume um viés multidimensional (político-jurídico, econômico e culturalista) e os movimentos dos agentes e grupos entrando e saindo de territórios (tidos como seus e de outros) manifesta os processos de desterritorializações e (re)territorializações (FUINI, 2017, p. 20).

O território é simultaneamente funcional e simbólico, pois, o domínio exercido sobre o espaço é condição para realizar funções e para produzir significados (HAESBAERT, 2004a). Assim, o território entendido a partir de sua forma mais concreta tem um caráter funcional e material e é caracterizado como um recurso dotado de valor de troca - base física, fonte de recurso. Por outro lado, o território concebido sob a batuta do aspecto simbólico está relacionado ao valor de uso abrigo, lar.

Assim sendo, o conceito de território tem íntima relação com o de poder, independentemente, deste ser calcado no campo de forças econômico, político ou cultural. Assumimos esta definição, compreendendo o território como espaço definido por e a partir de relações de poder, construído por múltiplos agentes sociais - sejam grupos sociais, empresas, Estado. 


\section{A PAISAGEM E O TERRITÓRIO NOS DOCUMENTOS OFICIAIS ORIENTADORES DO ENSINO ESCOLAR DE GEOGRAFIA}

A Geografia é disciplina escolar importante para a formação dos estudantes no âmbito da Educação Básica, tendo-se em vista o fato de o desenvolvimento do raciocínio espaço-temporal ser imprescindível para a formação de competências e habilidades concernentes à cidadania e ao mercado de trabalho. Destarte, é fundamental que os estudantes dos ensinos Fundamental e Médio apreendam a produção social do espaço, conhecendo e analisando fatos históricos e fenômenos naturais dessa produção, ocorrida em variadas escalas geográficas e com representação cartográfica (BRASIL, 2017).

No que tange aos anos finais do Ensino Fundamental, o ensino escolar de Geografia deve proporcionar competências e habilidades aos estudantes no sentido da identificação, conhecimento e comparação do lugar e do mundo e das relações entre estes, considerando-se diversas escalas e temporalidades, bem como distintos interesses sociais que, conjunturalmente e estruturalmente, organizam o espaço complexamente, por intermédio de relações de poder e de produção.

Desse modo, orientasse na Base Nacional Comum Curricular (BNCC) que

a área de Ciências Humanas deve propiciar aos alunos a capacidade de interpretar o mundo, de compreender processos e fenômenos sociais, políticos e culturais e de atuar de forma ética, responsável e autônoma diante de fenômenos sociais e naturais (BRASIL, 2017, p. 354).

Tendo-se em vista o destaque da Geografia para o desenvolvimento das competências e habilidades orientadas pela BNCC, sublinhamos o espaço geográfico como o principal conceito da Geografia, pois, o entendemos como categoria filosófica revelada enquanto objeto de estudo da ciência geográfica (SANTOS, 1988). A partir desse conceito, os estudantes da Educação Básica devem compreender quatro dimensões-chave para a análise ou interpretação da dinâmica da produção do espaço: território, paisagem, lugar e região. 
Destarte, abordamos as orientações constantes em documentos oficiais da Educação Básica nacional, quanto aos conceitos de paisagem e território. Assim, analisamos as orientações presentes nos Parâmetros Curriculares Nacionais (PCN), na BNCC e no Documento Curricular do Rio Grande do Norte (BNCC/RN) - por ser este estado o espaço da nossa práxis profissional. Não obstante o fato de a BNCC e o BNCC/RN serem documentos mais recentes, consideramos também os PCN, devido a esses parâmetros ainda serem muitos utilizados na organização da Educação Básica, inclusive, enquanto referenciais curriculares.

Os PCN orientam que a Geografia é a área de conhecimento comprometida em tornar o mundo compreensível para os estudantes; a disciplina escolar que deve explicar o mundo e colocar em tela transformações possíveis, considerando-se as diversas escalas geográficas, inclusive, a do lugar. Assim sendo, define-se como objetivo do ensino de Geografia o exame das relações históricas que marcam o processo de formação das sociedades humanas e de produção atual do espaço, com a adaptação da natureza, fatos que dinamizam paisagens e apropriam territórios.

A paisagem apresenta-se como conceito fundamental para o ensino e a aprendizagem em Geografia, sobretudo, no âmbito escolar, devido ao fato de a morfologia do espaço ser aspecto importante para os estudantes compreenderem a dinâmica da produção do espaço. Todavia, deve-se ter ciência que essa morfologia não é estática e meramente descritiva. É dinâmica e, nesse sentido, deve ser conhecida e analisada pelo entendimento dos processos sociais, físicos e ambientais condizentes aos variados contextos geográficos, dos particulares aos gerais.

Nos PCN (BRASIL, 1998, p. 28) define-se a paisagem como "uma unidade visível do território, que possui identidade visual, caracterizada por fatores de ordem social, cultural e natural, contendo espaços e tempos distintos; o passado e o presente. A paisagem é o velho no novo e o novo no velho!" Com outras palavras, dizemos que a paisagem expressa as marcas da história e realça a dinâmica do presente, apresentando o futuro como tendência. 
Outrossim, nos PCN se considera território e paisagem como conceitos que possuem semelhanças. Define-se, inclusive, o território como um conjunto de paisagens, criado pelo homem como forma de apropriação da natureza.

Quanto ao conceito de território, os PCN o abordam como espaço apropriado pelos homens, segundo a perspectiva ratzeliana. Na visão da geopolítica, trata-se o território como espaço nacional ou espaço controlado por um Estado-Nação. Do mesmo modo, frisa-se o território como categoria fundamental para se estudar a formação econômica e social de uma Nação. Assim, enquanto produto do trabalho humano, o território representa objetos e fluxos.

Nos PCN norteia-se o trabalho com o conceito de território e com a noção de territorialidade, pois, o território é o espaço apropriado pelos homens, composto de objetos e ações concretamente representados e imaterialmente normados. A territorialidade significa o uso do território, ou, em outras palavras, a condição necessária para a própria existência da sociedade, sendo que um mesmo território pode ser (re)produzido por meio de várias territorialidades, frequentes ou periódicas.

É evidente que a compreensão da dinâmica do território implica entender a complexidade das relações de convivência - nem sempre harmônicas - existentes em um espaço, considerando-se a diversidade de tendências, ideias, crenças, sistemas de pensamento e tradições. Em suma, faz-se mister apreender as diferentes forças que coexistem no espaço.

Nos PCN prevê-se o trabalho com os conceitos de paisagem e território em todas as séries do Ensino Fundamental II. Não obstante, recomenda-se o trabalho com a paisagem no $6^{\circ}$ e $7^{\circ}$ ano. O território no $8^{\circ}$ e $9^{\circ}$ ano do Ensino Fundamental. De modo geral, a abordagem de tais conceitos deve possibilitar a compreensão do espaço local conectado a escalas mais amplas - até a global, por meio da observação e/ou do estudo de situações existentes em variadas e conectadas escalas geográficas.

Na BNCC não são evidenciadas definições dos conceitos-chave da Geografia, mas sim habilidades que devem ser alcançadas com o desenvolvimento do processo de ensino e aprendizagem em Geografia. Destarte, no quadro 1 relacionamos essas 
habilidades com os conceitos de paisagem e de território, assim como com as séries do Ensino Fundamental II. Destacamos habilidades previstas na BNCC que possibilitam o trabalho com os conceitos de paisagem e território em todas as séries do Ensino Fundamental II, com foco essencial na compreensão da dinâmica do espaço.

Quadro 1: Trabalho com os conceitos de paisagem e território no ensino de Geografia no Ensino Fundamental, segundo a orientação de habilidades presente na BNCC, 2018

\begin{tabular}{|c|c|c|}
\hline Série & Habilidades necessárias para a compreensão do conteúdo & $\begin{array}{l}\text { Conceito } \\
\text { trabalhado }\end{array}$ \\
\hline $\begin{array}{l}6^{\circ} \\
\text { ano }\end{array}$ & $\begin{array}{l}\text { Comparar modificações das paisagens nos lugares de vivência e os usos } \\
\text { desses lugares em diferentes tempos. }\end{array}$ & Paisagem \\
\hline $\begin{array}{l}6^{\circ} \\
\text { ano }\end{array}$ & $\begin{array}{l}\text { Analisar modificações de paisagens por diferentes tipos de sociedade, } \\
\text { com destaque para os povos originários. }\end{array}$ & $\begin{array}{l}\text { Paisagem } \\
\text { território }\end{array}$ \\
\hline $\begin{array}{l}6^{\circ} \\
\text { ano }\end{array}$ & $\begin{array}{l}\text { Identificar as características das paisagens transformadas pelo trabalho } \\
\text { humano a partir do desenvolvimento da agropecuária e do processo de } \\
\text { industrialização. }\end{array}$ & Paisagem \\
\hline $\begin{array}{l}6^{\circ} \\
\text { ano }\end{array}$ & $\begin{array}{l}\text { Analisar distintas interações das sociedades com a natureza, com base } \\
\text { na distribuição dos componentes físico-naturais, incluindo as } \\
\text { transformações da biodiversidade local e do mundo. }\end{array}$ & Paisagem \\
\hline $\begin{array}{l}7^{\circ} \\
\text { ano }\end{array}$ & $\begin{array}{l}\text { Avaliar, por meio de exemplos extraídos dos meios de comunicação, } \\
\text { ideias e estereótipos acerca das paisagens e da formação territorial do } \\
\text { Brasil. }\end{array}$ & $\begin{array}{l}\text { Paisagem } \\
\text { território }\end{array}$ \\
\hline $\begin{array}{l}7^{\circ} \\
\text { ano }\end{array}$ & $\begin{array}{l}\text { Analisar a influência dos fluxos econômicos e populacionais na formação } \\
\text { socioeconômica e territorial do Brasil, compreendendo os conflitos e as } \\
\text { tensões históricas e contemporâneas. }\end{array}$ & $\begin{array}{l}\text { Paisagem } \\
\text { território }\end{array}$ \\
\hline $\begin{array}{l}7^{\circ} \\
\text { ano }\end{array}$ & $\begin{array}{l}\text { Selecionar argumentos que reconheçam as territorialidades dos povos } \\
\text { indígenas originários, das comunidades remanescentes de quilombos, de } \\
\text { povos das florestas e do cerrado, de ribeirinhos e caiçaras, entre outros } \\
\text { grupos sociais do campo e da cidade, como direitos legais dessas } \\
\text { comunidades. }\end{array}$ & $\begin{array}{l}\text { Paisagem } \\
\text { território }\end{array}$ \\
\hline $\begin{array}{l}7^{\circ} \\
\text { ano }\end{array}$ & $\begin{array}{l}\text { Analisar a distribuição territorial da população brasileira, considerando a } \\
\text { diversidade étnico-cultural (indígena, africana, europeia e asiática), assim } \\
\text { como aspectos de renda, sexo e idade nas regiões brasileiras. }\end{array}$ & Território \\
\hline $\begin{array}{l}7^{\circ} \\
\text { ano }\end{array}$ & $\begin{array}{l}\text { Estabelecer relações entre os processos de industrialização e inovação } \\
\text { tecnológica com as transformações socioeconômicas do território } \\
\text { brasileiro. }\end{array}$ & $\begin{array}{l}\text { Paisagem } \\
\text { território }\end{array}$ \\
\hline $\begin{array}{l}7^{\circ} \\
\text { ano }\end{array}$ & $\begin{array}{l}\text { Caracterizar dinâmicas dos componentes físico-naturais no território } \\
\text { nacional, bem como sua distribuição e biodiversidade (Floresta Tropical, } \\
\text { Cerrado, Caatinga, Campos e Mata de Araucária). }\end{array}$ & $\begin{array}{l}\text { Paisagem } \\
\text { território }\end{array}$ \\
\hline
\end{tabular}


Quadro 1: Conclusão...

\begin{tabular}{|c|c|c|}
\hline $\begin{array}{l}8^{\circ} \\
\text { ano }\end{array}$ & $\begin{array}{l}\text { Compreender os fluxos de migração na América Latina (movimentos } \\
\text { voluntários e forçados, assim como fatores e áreas de expulsão e } \\
\text { atração) e as principais políticas migratórias da região. }\end{array}$ & Território \\
\hline $\begin{array}{l}8^{\circ} \\
\text { ano }\end{array}$ & $\begin{array}{l}\text { Aplicar os conceitos de Estado, nação, território, governo e país para o } \\
\text { entendimento de conflitos e tensões na Contemporaneidade, com } \\
\text { destaque para as situações geopolíticas na América e na África e suas } \\
\text { múltiplas regionalizações a partir do pós-guerra. }\end{array}$ & Território \\
\hline $\begin{array}{l}8^{\circ} \\
\text { ano }\end{array}$ & $\begin{array}{l}\text { Analisar áreas de conflito e tensões nas regiões de fronteira do } \\
\text { continente latino-americano e o papel de organismos internacionais e } \\
\text { regionais de cooperação nesses cenários. }\end{array}$ & Território \\
\hline $\begin{array}{l}8^{\circ} \\
\text { ano }\end{array}$ & $\begin{array}{l}\text { Analisar as principais problemáticas comuns às grandes cidades latino- } \\
\text { americanas, particularmente aquelas relacionadas à distribuição, } \\
\text { estrutura e dinâmica da população e às condições de vida e trabalho. }\end{array}$ & $\begin{array}{l}\text { Paisagem } \\
\text { território }\end{array}$ \\
\hline $\begin{array}{l}8^{\circ} \\
\text { ano }\end{array}$ & $\begin{array}{l}\text { Analisar a segregação socioespacial em ambientes urbanos da América } \\
\text { Latina, com atenção especial ao estudo de favelas, alagados e zona de } \\
\text { riscos. }\end{array}$ & $\begin{array}{l}\text { Paisagem } \\
\text { território }\end{array}$ \\
\hline $\begin{array}{l}9^{\circ} \\
\text { ano }\end{array}$ & $\begin{array}{l}\text { Analisar criticamente de que forma a hegemonia europeia foi exercida } \\
\text { em várias regiões do planeta, notadamente em situações de conflito, } \\
\text { intervenções militares e/ou influência cultural em diferentes tempos e } \\
\text { lugares. }\end{array}$ & Território \\
\hline $\begin{array}{l}9^{\circ} \\
\text { ano }\end{array}$ & $\begin{array}{l}\text { Identificar diferentes manifestações culturais de minorias étnicas como } \\
\text { forma de compreender a multiplicidade cultural na escala mundial, } \\
\text { defendendo o princípio do respeito às diferenças. }\end{array}$ & $\begin{array}{l}\text { Paisagem } \\
\text { território }\end{array}$ \\
\hline $\begin{array}{l}9^{\circ} \\
\text { ano }\end{array}$ & $\begin{array}{l}\text { Relacionar diferenças de paisagens aos modos de viver de diferentes } \\
\text { povos na Europa, Ásia e Oceania, valorizando identidades e } \\
\text { interculturalidades regionais. }\end{array}$ & $\begin{array}{l}\text { Paisagem } \\
\text { território }\end{array}$ \\
\hline $9^{\circ}$ & $\begin{array}{l}\text { Analisar os componentes físico-naturais da Eurásia e os determinantes } \\
\text { histórico-geográficos de sua divisão em Europa e Ásia. }\end{array}$ & $\begin{array}{l}\text { Paisagem } \\
\text { território }\end{array}$ \\
\hline $\begin{array}{l}9^{\circ} \\
\text { an }\end{array}$ & $\begin{array}{l}\text { Analisar transformações territoriais, considerando o movimento de } \\
\text { fronteiras, tensões, conflitos e múltiplas regionalidades na Europa, na } \\
\text { Ásia e na Oceania. }\end{array}$ & Território \\
\hline
\end{tabular}

Fonte: Adaptado da BNCC (BRASIL, 2018)

No Rio Grande do Norte, foi proposto o BNCC/RN (RIO GRANDE DO NORTE, 2018) em decorrência do trabalho colaborativo envolvendo agentes das redes municipais, estadual e privada de ensino, além dos conselhos estadual e municipais de Educação.

Neste documento são apresentadas definições dos conceitos geográficos. A paisagem é considerada segundo a teoria proposta por Milton Santos, entendendo-a como unidade visível do arranjo espacial, alcançada por nossa visão. Além disso, é entendida como a materialização de um instante pela sociedade, sendo heterogênea, por se constituir em conjunto de objetos de diferentes momentos. 
O conceito de território é definido como produto da materialidade técnica das sociedades, com delimitação decorrente das relações de poder. Além disso, orienta-se que o conceito de território seja trabalhado de modo contextualizado, isto é, conectando-se aspectos da Globalização com a dinâmica do espaço vivido pelos estudantes e professores. Do mesmo modo, conforme a perspectiva da Geografia Crítica, destaca-se a pertinência de se atentar para as desigualdades sociais e econômicas existentes no território, para que, assim, se possa refletir e agir no sentido de transformações sociais e espaciais urgentes.

Este documento recomenda que no $6^{\circ}$ ano do Ensino Fundamental sejam trabalhos os conteúdos identidade sociocultural, reconhecimento dos lugares de vivência e os diferentes e desiguais usos do espaço visando a aprendizagem sobre a interferência humana no planeta. Assim, destacamos a pertinência da abordagem do conceito de território e da noção de territorialidade ou território usado. Outrossim, o conceito de paisagem pode ser abordado nesse ano para que os estudantes apreendam as diversas formas de ocupação do espaço pelos homens, em diferentes períodos históricos, atentando-se para os vários conflitos existentes neste processo.

No $7^{\circ}$ ano do Ensino Fundamental pode-se trabalhar amplamente o conceito de território, tendo-se em vista o destaque que se dá aos conteúdos formação territorial do Brasil; dinâmicas sociocultural, econômica e política; processo de formação do Rio Grande do Norte; e transformações e usos desiguais do território brasileiro.

Nos dois últimos anos do Ensino Fundamental foca-se o estudo no espaço mundial, sendo pertinente o trabalho com os conceitos de território e região. No $8^{\circ}$ ano sublinha-se o ensino e a aprendizagem da América e da África. No $9^{\circ}$ ano, orientase o estudo da Europa, do processo de Globalização, da constituição do Estado Moderno e de disputas territoriais.

Destarte, conforme os documentos oficiais orientadores da educação que aqui analisamos, asseveramos que os conceitos de paisagem e território podem ser tratados em todos os anos do Ensino Fundamental II, estudados de forma específica enquanto conceitos a serem definidos, ou de modo amplo e aplicado - os utilizando 
para compreender a dinâmica do espaço. Além disso, é notório que se orienta o entendimento da paisagem enquanto imagem do espaço, seguindo a compreensão do geógrafo Milton Santos. Não obstante, destacamos que a paisagem deve ser estudada pela sua morfologia, cujo entendimento, em essência, ultrapassa o sentido da visão, envolvendo também outros sentidos, bem como aspectos históricos do passado, do presente e tendências do futuro. Com esse sentido, a paisagem apresenta-se como memória do passado, evidência da atual dinâmica e devir. Por sua vez, o território é definido como o espaço apropriado pelos homens por meio de relações de poder. Assim, o território é caracterizado por múltiplas intencionalidades ou usos, fato que torna pertinente também o trabalho com a noção de territorialidade ou, nas palavras de Milton Santos, de uso do território.

\section{OS CONCEITOS DE PAISAGEM E DE TERRITÓRIO EM LIVROS DIDÁTICOS DE GEOGRAFIA}

A utilização do livro didático no processo de ensino e aprendizagem é analisada, muitas vezes, na perspectiva da ortodoxia, sendo que alguns educadores defendem essa utilização como imprescindível, enquanto que outros propõem o seu descarte.

Segundo Albuquerque (2011), essas visões cindidas ou ortodoxas se explicam pela história de produção e análise do livro didático. Durante muito tempo - até a segunda metade do século $X X$, o livro didático era considerado por boa parte dos professores e da comunidade escolar - de modo genérico - como material didático de segunda categoria, inferior a apostilas, por exemplo. Todavia, a partir da década de 1990, a produção do livro didático foi transformada, ampliando a sua utilização, assim como a análise dessa produção e utilização torna-se objeto de pesquisas acadêmicas.

Assim, na atualidade, para Schäffer (2006, p. 97), “o livro didático é, por excelência, o texto escrito de caráter informativo, aquele ao qual se credita fidedignidade de informação". A sua leitura pode proporcionar o aprofundamento de 
conceitos que auxiliarão no desenvolvimento do processo de ensino e aprendizagem de modo contextualizado.

Neste tópico discutimos como os conceitos de paisagem e de território são abordados em livros didáticos, adotando como recorte analítico da pesquisa escolas do Ensino Fundamental II da rede pública estadual de ensino na cidade de Santa Cruz (RN) (mapa 1), por ser esta a nossa realidade profissional.

Sendo assim, inicialmente, pesquisamos quais livros didáticos de Geografia foram adotados pelos professores de Geografia no triênio 2017-2019, para o Ensino Fundamental $\|^{6}$. Constatamos que houve certa homogeneidade nas escolhas realizadas pelos docentes, pois, foram selecionadas apenas duas coleções: Vontade de Saber Geografia e Geografia, Espaço e Vivência.

Mapa 1: Destaque do Rio Grande do Norte no Brasil e do município de Santa Cruz no território potiguar

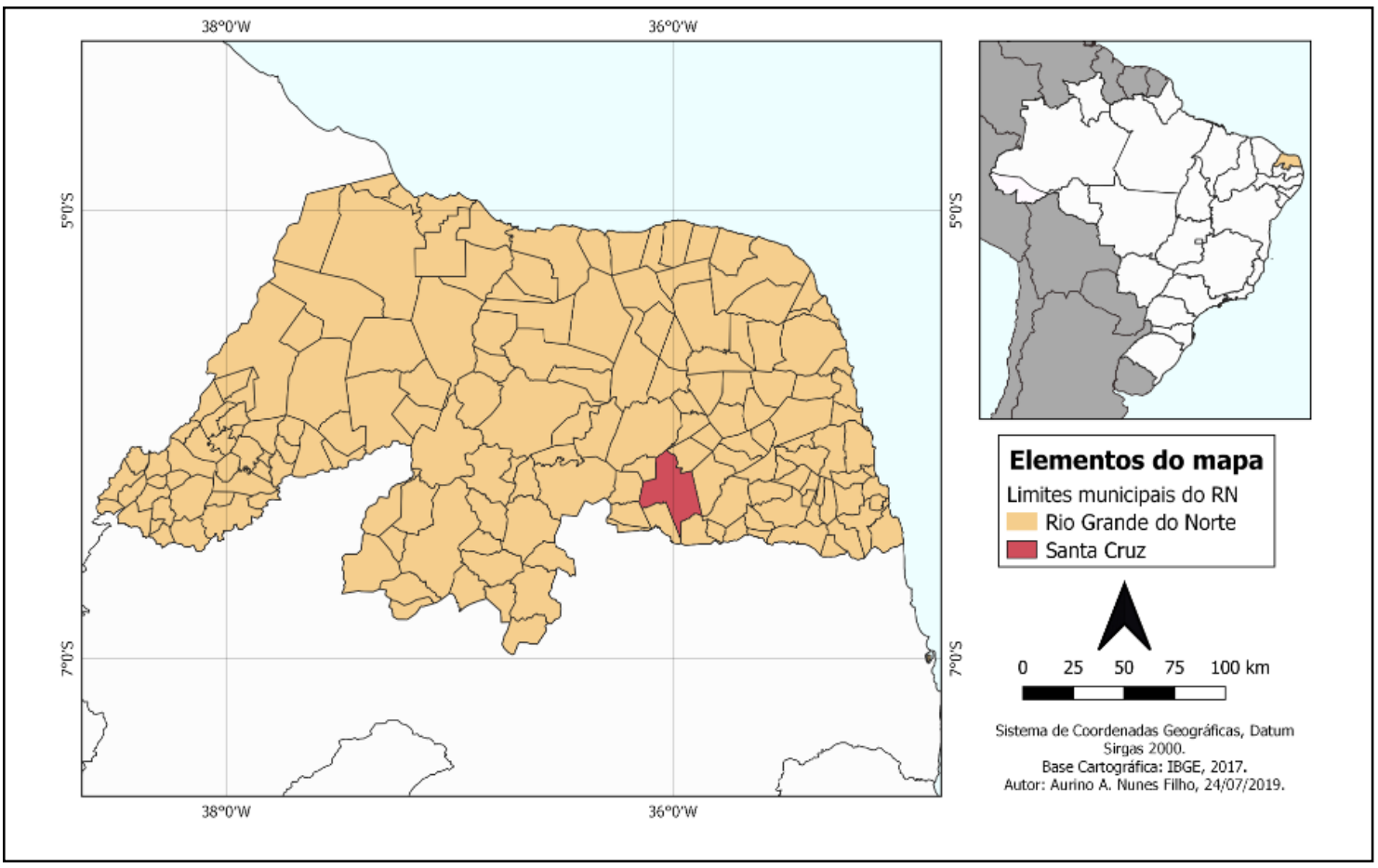

Fonte de dados: IBGE (2017)

Elaboração cartográfica: Aurino Alves Nunes Filho, 2019

\footnotetext{
${ }^{6}$ Este intervalo de tempo foi escolhido por compreender o período em que esta pesquisa foi desenvolvida, bem como ser o período de vigência das coleções - escolhidas pelos docentes - aprovadas no edital de 2017 do Programa Nacional do Livro Didático (PNLD).
} 
A coleção Vontade de Saber Geografia foi editada pela FTD, tem como autora Neiva Camargo Torrezani; foi selecionada em cinco escolas públicas da cidade de Santa Cruz ${ }^{7}$ A coleção Geografia, Espaço e Vivência foi editada pela Saraiva, tendo como autores Levon Boligian, Rogério Martinez, Andressa Tucatel Alves Boligian e Wanessa Pires Garcia Vidal; foi escolhida em uma escola ${ }^{8}$.

\section{1 o conceito de paisagem nos livros didáticos}

Na coleção Vontade de Saber Geografia, o primeiro capítulo do livro do $6^{\circ}$ ano do Ensino Fundamental é dedicado aos conceitos de lugar, paisagem e espaço geográfico. Entretanto, a paisagem é mais abordada que os outros conceitos, inclusive, tendo mais páginas destinadas à sua discussão.

A autora busca associar tais conceitos afirmando que cada lugar tem diferentes paisagens. Define a paisagem como tudo aquilo que se vê em determinado lugar e em um dado momento. Assim, valoriza-se o aspecto visível da paisagem, embora a autora do livro didático ressalte que algumas características da paisagem também podem ser percebidas por meio de sons, odores e movimentos. Esse entendimento está fundamentado no conceito proposto por Santos (1988b, p. 61), de que a paisagem é "tudo aquilo que nós vemos, o que nossa visão alcança [...]. Esta pode ser definida como o domínio do visível, aquilo que a vista abarca. Não é formada apenas de volumes, mas também de cores, movimentos, odores, sons etc."

No livro faz-se uma sugestão de atividade para o professor desenvolver junto com os estudantes, a fim de que se apreenda a paisagem de forma prática. Trata-se de um exercício para os estudantes compreenderem os elementos da paisagem, por meio de outros sentidos diferentes do da visão. Assim, os discentes devem tocar e/ou cheirar objetos selecionados pelo professor, bem como utilizarem a audição em uma caminhada realizada com os olhos vendados. Tal exercício estimula a curiosidade do

\footnotetext{
7 Escola Estadual João Ferreira de Souza, Escola Estadual Cosme Ferreira Marques, Escola Estadual Quintino Bocaiúva, Escola Estadual Professora Rita Nely Furtado e Escola Estadual Pedro Severino Bezerra.

8 Escola Estadual Isabel Oscarlina Marques.
} 
estudante e possibilita um processo investigativo calcado na criatividade, imaginação e reflexão, conforme proposto na BNCC enquanto competência geral:

Exercitar a curiosidade intelectual e recorrer à abordagem própria das ciências, incluindo a investigação, a reflexão, a análise crítica, a imaginação e a criatividade, para investigar causas, elaborar e testar hipóteses, formular e resolver problemas e criar soluções (inclusive tecnológicas) com base nos conhecimentos das diferentes áreas (BRASIL, 2017, p. 09).

Ademais, se esclarece que as diferentes paisagens são caracterizadas por elementos naturais, culturais ou pela soma destes. Os elementos naturais, segundo a autora do livro, são rios, oceanos, formas de relevo e vegetação decorrentes de processos naturais. Os elementos culturais são casas, edifícios, rodovias, lavouras.

Nesse sentido, propõe-se no livro exercício para que os estudantes analisem uma fotografia e identifiquem os planos da paisagem e o conjunto de elementos que cada um dos planos evidencia. Desse modo, objetiva-se que os estudantes analisem e comparem os conjuntos de elementos da paisagem - tanto os naturais quanto os decorrentes das ações humanas, segundo habilidades colocadas em baila pela BNCC: “Comparar modificações das paisagens nos lugares de vivência e os usos desses lugares em diferentes tempos. Analisar modificações de paisagens por diferentes tipos de sociedade, com destaque para os povos originários (BRASIL, 2017, p. 383)".

Corroborando com Santos (1988a), que considera a paisagem natural como aquela ainda não alterada pelo esforço do homem, Torrezani (2015) entende que as paisagens naturais são formadas apenas por elementos da natureza, sem interferência da ação humana. Por outro lado, as paisagens culturais - também denominadas de paisagens artificiais ou humanizadas - têm a predominância de elementos produzidos pelo homem. Assim, a autora destaca que as paisagens naturais são cada vez mais raras, tendo-se em vista o fato de que para elas existirem não pode haver qualquer intervenção humana, direta ou indireta. 
A morfologia da paisagem é destacada como sendo dinâmica, pois,

ao observarmos uma paisagem pela segunda vez não a veremos exatamente como a vimos pela primeira. Isso acontece porque as paisagens estão em constante transformação, que ocorre em períodos diversos e com diferentes durações. Algumas são modificadas pela natureza, seja pela força da dinâmica interna da Terra, como vulcões e terremotos, seja pela ação de agentes externos, como os ventos, as águas das chuvas e dos rios. Outras paisagens são alteradas pela ação humana por meio da construção ou reforma de edifícios e casas, abertura de novas ruas e até mesmo pelo movimento de carros e pessoas. Cada uma dessas transformações afeta a paisagem em maior ou menor grau, dependendo de sua intensidade e natureza (TORREZANI, 2015, p. 26).

O aprendizado de que a paisagem é dinâmica proporciona ao estudante a habilidade de "analisar distintas interações das sociedades com a natureza, com base na distribuição dos componentes físico-naturais, incluindo as transformações da biodiversidade local e do mundo" (BRASIL, 2017, p. 383).

O modo e a velocidade de modificação da paisagem pela ação humana é definida por meio do trabalho e da técnica. Sublinha-se o trabalho como as atividades realizadas pelo homem a fim de suprir as suas necessidades e que, por intermédio dessas, o ser humano se relaciona com a natureza e a transforma, modificando, assim, paisagens. Da mesma maneira, "as técnicas consistem na aplicação dos conhecimentos desenvolvidos pelas pessoas nos modos de trabalho ou na criação de ferramentas e de outros instrumentos para a realização de um trabalho" (TORREZANI, 2015, p. 29).

Essas definições são condizentes com competência específica do ensino e aprendizagem de Geografia no Ensino Fundamental, quando se orienta que os estudantes sejam capazes de reconhecerem a importância dos objetos técnicos para a compreensão das formas como os seres humanos fazem uso dos recursos da natureza ao longo da história, bem como de identificar as características das 
paisagens transformadas pelo trabalho humano a partir do desenvolvimento da agropecuária e do processo de industrialização e de explicar as mudanças na interação humana com a natureza a partir do surgimento das cidades (BRASIL, 2017).

Além disso, no livro didático faz-se referência ao tempo das técnicas, devido ao fato de técnicas rudimentares e sofisticadas caracterizarem, conjuntamente, a transformação da paisagem. Assim, a paisagem é produzida por acréscimos e sobreposições, sendo um conjunto de objetos com idades e heranças diferentes; elementos de outrora e do presente marcam a paisagem atual (SANTOS, 1988a).

Nos livros subsequentes da coleção o conceito de paisagem não é discutido com destaque, sendo utilizado, de modo geral, na denominação de ilustrações de biomas e climas. Outrossim, no livro do $9^{\circ}$ ano, sobretudo, o termo paisagem é utilizado em ilustrações de situações de vulnerabilidade social e contrates socioeconômicos.

No livro Geografia, Espaço e Vivência são dedicados dois capítulos para a discussão da paisagem. Os autores fazem a opção de aproximar tal conceito com o de lugar, pois, entendem que a morfologia da paisagem é que diferencia os lugares. Assim sendo, a superfície terrestre seria uma infinidade de lugares com paisagens diferentes.

Entende-se que a paisagem pode ser natural ou cultural. Na paisagem natural há o predomínio de elementos da natureza, como as cadeias montanhosas, os desertos, as florestas e as geleiras. A paisagem cultural é produto da sociedade, como edifícios, casas, arruamentos, fábricas, plantações e estradas.

Com esse entendimento, no livro didático motiva-se os estudantes a pensarem em paisagens naturais e culturais que eles conhecem e/ou que gostariam de conhecer, tendo-se em vista a competência geral orientada na BNCC (BRASIL, 2017) de o estudante realizar seleções a partir da criatividade, imaginação e reflexão.

Assim como no livro didático anteriormente analisado, em Geografia, Espaço e Vivência afirma-se aos estudantes que a compreensão da paisagem pode ser realizada por meio de planos, do mais próximo ao mais distante. Nesse sentido, orienta-se que 
os estudantes analisem os elementos da paisagem em planos, com a realização de comparações visando a compreensão das modificações e dos usos históricos da paisagem pelos homens. Destarte, conceitua-se a paisagem como o conjunto de formas e conteúdos decorrentes das históricas relações entre o homem e a natureza: "As paisagens expressam a relação dos seres humanos com o espaço que vivem" (BOLIGIAN et al, 2015, p. 18).

Frisa-se a importância do homem na transformação da paisagem, tendo-se em vista a celeridade com que as paisagens naturais vêm sendo modificadas ao longo dos anos. Acerca disto, são evidenciadas três ilustrações de uma mesma paisagem, referentes a momentos diferentes. Assim sendo, aborda-se a paisagem como um conjunto de formas heterogêneas, com idades e maneiras de produção diferentes, segundo as reflexões propostas por Santos (1988a). Essa abordagem possibilita que os estudantes identifiquem e interpretem mudanças ocorridas no tempo e no espaço, tendo-se em vista a importância do trabalho e da técnica no processo de transformação da paisagem natural em cultural. Tal possibilidade é coerente com habilidade destacada nas diretrizes curriculares para o ensino e aprendizagem de Geografia no Ensino Fundamental no Rio Grande do Norte, a saber: identificar e interpretar as mudanças ocorridas nas paisagens rurais e urbanas no tempo e no espaço (BNCC/RN, 2018).

Em suma, constatamos que em ambas as coleções de livros didáticos as discussões sobre o conceito de paisagem estão concentradas nos primeiros capítulos dos livros do $6^{\circ}$ ano do Ensino Fundamental, evidenciando-se, de modo genérico, 0 entendimento da paisagem como sendo dinâmica e transtemporal, estando em constante transformação pela ação humana.

\section{2 o conceito de território nos livros didáticos}

Na coleção Vontade de Saber Geografia não se destina uma parte do livro para a discussão do conceito de território. Identificamos a utilização do termo território mais presente nos primeiros capítulos dos livros do $7^{\circ}$ e do $8^{\circ}$ ano do Ensino Fundamental. 
Entende-se o território em conformidade com a perspectiva da Geografia Clássica ratzeliana, associando-se o território à delimitação do espaço nacional, ao domínio jurídico-político ou, simplesmente, a solo - base física a ser explorada. Com esse sentido, são colocadas em baila as noções de limite e fronteira:

Limite é a linha que determina e separa os domínios de dois ou mais territórios, como de um país, estado ou município. [...] toda vez que nos referimos à fronteira, estamos mencionando uma faixa, ou seja, uma zona do território, geralmente habitada, que se estende ao longo da linha limite (TORREZANI, 2015, p. 16-17).

Trata-se também do processo de ocupação e formação do território brasileiro, não destacando, contudo, as disputas de poder entre os nativos, os diversos povos europeus e africanos, que caracterizaram este processo.

No livro do $9^{\circ}$ ano do Ensino Fundamental, mantém-se o entendimento acerca do território calcado nas noções de limites e fronteiras e no domínio jurídico-político:

O território europeu é um prolongamento do continente asiático, estando a ele diretamente conectado via terrestre. A definição dos limites da Europa oriental com a Ásia sempre foi uma tarefa bastante controversa entre os geógrafos. Para resolver essa questão, foi necessário dividir o território russo entre os dois continentes: ao meio dele, em sentido longitudinal (norte-sul), passa os Montes Urais, uma antiga cordilheira já bastante desgastada, ao longo da qual se estabeleceu uma fronteira, imaginária, que separa a Europa da Ásia (TORREZANI, 2015, p. 15).

Ao longo dessa coleção de livros didáticos são colocados em baila conteúdos que poderiam ser trabalhadas de modo intrínseco à discussão do conceito de território, como dimensão simbólica, identidade, relações de poder, contradições e tensões, espaços construídos e descontruídos socialmente. Não obstante, tais conteúdos não são abordados considerando-se o conceito de território, o que vai de encontro com o que é orientado no Documento Curricular do Estado do Rio Grande do Norte para o Ensino Fundamental (RIO GRANDE DO NORTE, 2018), quando se destaca a 
importância da compreensão do território enquanto porção do espaço definida pelas relações de poder, sendo, dessa forma, produto da materialidade técnica da sociedade, cuja delimitação decorre das relações de poder, domínio e apropriação.

No livro didático do $8^{\circ}$ ano do Ensino Fundamental apresenta-se definição de território, na perspectiva do caráter estatal, de domínio e gestão de uma área.

Para a Geografia, território representa uma área sobre a qual se exerce domínio, isto é, relações de poder, propriedade e influência. Os países são territórios que correspondem a uma área continental ou insular da superfície terrestre, dominada e organizada politicamente, por um sistema de governo, leis e instituições próprias. O Estado é a autoridade máxima em um país que exerce controle sobre o território nacional (TORREZANI, 2015, p. 44, grifos nossos).

No livro Geografia, Espaço e Vivência coloca-se em tela compreensão semelhante acerca do conceito de território. Ao referir-se ao território brasileiro, Boligian et al (2015, p. 12) asseveram que é a "porção da superfície terrestre sobre a qual a nação brasileira exerce domínio e soberania". Assim, sublinhamos a clara influência das ideias ratzelianas sobre esse entendimento.

Também se dá ênfase às noções de limite e fronteira, inclusive, exemplificando que a fronteira do Estado brasileiro não se limita às terras emersas, mas também é composta por uma fronteira marítima, na qual o Brasil exerce autonomia e soberania.

Ao tratar do processo de formação do território brasileiro, expõe-se que a ocupação portuguesa em terras que, mais tarde, viriam a ser o Brasil, foi a responsável pelas diversas transformações que ocorreram neste território, deixando marcas na paisagem e contribuindo para a formação da cultura e do espaço geográfico do país. Todavia, Boligian et all (2015) não deixam esclarecido aos estudantes o intenso jogo de forças que marca essa construção histórica que é o território nacional.

Além de discutir limites, fronteiras, nação, Estado e território nacional, o livro didático em questão também evidencia conteúdos sobre questões territoriais de 
povos que não têm soberania sobre território, assim como de povos que ocupam um território ou que estão em busca de um espaço para delimitarem conforme a sua soberania.

Não obstante nos livros didáticos analisados serem trazidas à tona discussões importantes sobre questões territoriais e, especificamente, acerca do território brasileiro, a nosso ver, é necessário avançar na discussão acerca do conceito de território, pois, atualmente, novas abordagens teóricas estão disponíveis no sentido da compreensão do território enquanto dimensão concreta de análise do espaço geográfico caracterizada pelas relações de poder entre os diversos agentes sociais e concernentes às diversas escalas geográficas.

\section{CONSIDERAÇÕES FINAIS}

Das dimensões concretas de análise do espaço geográfico, asseveramos o território e a paisagem para o contexto da Geografia escolar, uma vez que a dinâmica da produção do espaço, envolvendo variadas escalas geográficas, pode ser compreendida por meio do entendimento da morfologia dos lugares e das relações de poder e de produção que caracterizam as ações de organização do espaço. Com essa compreensão, pode-se contextualizar o processo educacional em Geografia, atribuindo significado real ou prático a conteúdos programáticos.

Cabe ao professor de Geografia ter domínio das diferentes conceptualizações de paisagem e de território na história do pensamento geográfico, assim como saber das diretrizes e orientações para a Educação nacional quanto a esses conceitos. Destarte, o professor poderá ensinar tais conceitos de modo pertinente ao cotidiano vivenciado pelos estudantes e, assim, mediar o processo de ensino e aprendizagem em Geografia com a possibilidade de os estudantes apreenderem conteúdos e também produzirem entendimentos, relacionando conceitos com dinâmicas da produção do espaço, inclusive, na escala local.

Outrossim, destacamos o importante papel do livro didático no processo educacional, tendo-se em vista o fato desse material didático ser acessível a 
professores e estudantes das escolas públicas do Brasil e ter a sua forma e seu conteúdo melhorados constantemente. Hoje, há livros didáticos que evidenciam conteúdos programáticos de modo ilustrado e remetendo a vários outros materiais complementares, como livros, notícias, vídeos, músicas. Outrossim, mais e mais, são recomendadas atividades que relacionam os conteúdos abordados com pesquisa sobre as realidades vividas pelos estudantes. Não obstante, frisamos também a pertinência de o professor não limitar o processo de ensino e aprendizagem ao livro didático. Outros materiais devem ser buscados e consultados, inclusive, a partir de indicações presentes no próprio livro didático adotado pela escola, assim como recursos didáticos - como maquetes, mapas, cartilhas, vídeos - podem ser produzidos pelos agentes sociais envolvidos no processo educacional, visando a aprendizagem significativa de conteúdos programáticos. No que se refere, especificamente, ao ensino de Geografia, realçamos a pertinência de se ensinar e apreender conteúdos por intermédio do entendimento e da produção de conceitos de maneira contextualizada à dinâmica do espaço geográfico, considerando-se correlações de diferentes escalas geográficas, remetendo-se sempre a escala local.

Em suma, afirmamos que o ensino escolar de Geografia deve proporcionar aos estudantes a reflexão acerca do espaço geográfico - enquanto objeto da ciência e da disciplina escolar e instância da sociedade - e o entendimento das dimensões concretas de análise do espaço - como a paisagem e o território, mirando a compreensão crítica do presente por cidadãos que podem produzir um futuro melhor, do ponto de vista do bem-estar social.

\section{REFERÊNCIAS}

ALBUQUERQUE, M. A. M. Livros didáticos e currículos de Geografia, pesquisas e usos: uma história a ser contada. In: TONINI, I. M.; GOULART, L. B.; MARTINS, R. E. M. W.; CASTROGIOVANNI, A. C.; KAERCHER, N. A. O ensino de Geografia e suas composições curriculares. Porto Alegre: UFRGS, 2011. 
ANDRADE, M. C. Territorialidades, desterritorialidades, novas territorialidades: os limites do poder nacional e do poder local. In: SANTOS, M.; SOUZA, M. A. A.; SILVEIRA, M. L. (Org.) Território, globalização e fragmentação. São Paulo: Hucitec, 1998.

BERTRAND, G. Paisagem e Geografia Física Global: esboço metodológico. RA'E GA, $n$. 8, p. 141-152, 2004.

BOLIGIAN, L. et al. Geografia, espaço e vivência. $6^{\circ}$ ano. $5^{a}$ Ed. São Paulo: Ed. Saraiva, 2015.

BOLIGIAN, L. et al.. Geografia, espaço e vivência. $7^{\circ}$ ano. $5^{a}$ Ed. São Paulo: Ed. Saraiva, 2015.

BOLIGIAN, L. et al.. Geografia, espaço e vivência. $8^{\circ}$ ano. $5^{a}$ Ed. São Paulo: Ed. Saraiva, 2015.

BOLIGIAN, L. et al. Geografia, espaço e vivência. $9^{\circ}$ ano. $5^{a}$ Ed. São Paulo: Ed. Saraiva, 2015.

BRASIL. Secretaria de Educação Fundamental. Parâmetros Curriculares Nacionais: terceiro e quarto ciclos do Ensino Fundamental - Geografia. Brasília: MEC/SEF, 1998.

BRASIL. Secretaria de Educação Básica. Base Nacional Comum Curricular: Ensino Fundamental. Brasília, 2017.2 Disponível em: http://basenacionalcomum.mec.gov.br/images/BNCC_El_EF_110518_versaofinal_site.p df. Acesso em: 02 de mar de 2019.

CORRÊA, R. L. Territorialidade e corporação: um exemplo. In: SANTOS, M.; SOUZA, M. A. A.; SILVEIRA, M. L. (Org.) Território, Globalização e fragmentação. São Paulo: Hucitec, 1998.

COSGROVE, D. A Geografia está em toda parte: cultura e simbolismo nas paisagens humanas. In: CORRÊA, R. L.; ROSENDAHL, Z. (Org.) Paisagem, tempo e cultura. Rio de Janeiro: EdUERJ, 1998.

DEMATTEIS, G. Le metafore della terra. La geografia umana tra mito e scienza. Milano: Feltrinelli, 1985.

FUINI, L. L. O território em Rogério Haesbaert: concepções e conotações. Geografia, Ensino \& Pesquisa, v. 21, n.1, p. 19-29, 2017.

GANDY, M. Paisagem, estéticas e ideologia. CORREA, R. L. ROSENDAHL, Z. (Org.). Paisagens, textos e identidade. Rio de Janeiro: EdUERJ, 2004, p.75-90. 
RIO GRANDE DO NORTE. Secretaria do Planejamento e das Finanças. Secretaria de Educação e Cultura. Fundação Vanzolini. Construção das diretrizes e matrizes curriculares para a rede estadual de Educação Básica do Rio Grande do Norte. 2018.

http://www.rnsustentavel.rn.gov.br/smiv3/site/conteudos/midias/d3a25d505622e8db f75bd03c54319da6.pdf. Acesso em: 20 abr. 2020.

HAESBAERT, R. Dos múltiplos territórios à multiterritorialidade. In: HEIDRICH, A.; COSTA, B.; PIRES, C.; UEDA, V. (Org.) A emergencia da multiterritorialidade: a ressignifcação da relação do humano com o espaço. Canoas/Porto Alegre: Editora ULBRA, Editora da UFRGS, $2004 a$.

HAESBAERT, R.. O mito da desterritorialização: do "fim dos territórios" à multiterritorialidade. Rio de Janeiro: Bertrand Brasil, 2004b.

MORAES, A. C. R. (org.) Ratzel. São Paulo: Ática, 1990.

RAFFESTIN, C. Por uma Geografia do poder. São Paulo: Ática, 1993.

RATZEL, F. Geografia do homem: antropogeografia. Tradução de Fátima Murad. In: MORAES, A. C. R. (org.) Ratzel. São Paulo: Ática, 1990. p. 32-107.

SALGUEIRO, T. B. Paisagem e Geografia. Finisterra, n. 72, p. 37-53, 2001.

SANTOS, M. Por uma Geografia Nova: da crítica da Geografia a uma Geografia Crítica. São Paulo: Hucitec, 1978.

SANTOS, M. O espaço geográfico como categoria filosófica. Terra Livre, n. 5, p. 09-20, 1988.

SANTOS, M. A natureza do espaço: técnica e tempo, razão e emoção. São Paulo: Hucitec, 1996.

SANTOS, M. Estrutura, processo, função e forma como categorias do método geográfico. In: Espaço e método. 5 ed. São Paulo: EDUSP, 2008. p. 67-79.

SAQUET, M. A. Abordagens e concepções sobre território. São Paulo: Expressão Popular, 2007.

SAUER, C. O. A morfologia da paisagem. In: CORRÊA, R. L.; ROSENDAHL, Z. (Org.) Paisagem, tempo e cultura. Rio de Janeiro: EdUERJ, 1998. 124p. 
SCHÄFFER, N. O. Ler a paisagem, o mapa, o livro. Escrever nas linguagens da Geografia. In: NEVES, I. C. B.; SOUZA, J. V.; SCHÄFFER, N. O.; GUEDES, P. C.; KLÜSENER, R. Ler e escrever: compromisso de todas as áreas. Porto Alegre: Editora da UFRGS, 2006, p. 86-101.

SOUZA, M. J. L. O território: sobre espaço e poder, autonomia e desenvolvimento. In: CASTRO, I. E.; GOMES, P. C. C.; CORRÊA, R. L. (Org.), Geografia: conceitos e temas. Rio de Janeiro: Bertrand Brasil, 1995. p. 77-116.

SPOSITO, E. S. Geografia e Filosofia: contribuição para o ensino do pensamento geográfico. São Paulo: Editora da UNESP, 2004.

TORREZANI, N. C. Vontade de saber Geografia. 6ªno. 2. Ed. São Paulo: FTD, 2015.

TORREZANI, N. C.. Vontade de saber Geografia. $7^{\circ}$ ano. 2. Ed. São Paulo: FTD, 2015.

TORREZANI, N. C.. Vontade de saber Geografia. $8^{\circ}$ ano. 2. Ed. São Paulo: FTD, 2015.

TORREZANI, N. C.. Vontade de saber geografia. $9^{\circ}$ ano. 2. Ed. São Paulo: FTD, 2015.

TRICART, J. L. F. Paisagem e Ecologia: São Paulo: Igeo/USP, 1981. 